\title{
A comparison of quantitative methods in the investigation of urinary infections
}

\author{
R. A. OSBORN AND A. J. SMITH \\ From the Departments of Bacteriology and of Therapeutics, the Royal Infirmary, Sheffield
}

SYNOPSIS Bacterial colony counts and urinary white and non-squamous epithelial cell excretion rates have been compared in successive urine samples from 51 hospital patients. In all 19 cases withor a colony count greater than $100,000 / \mathrm{ml}$. the cell excretion rate was over $200,000 /$ hour. Urinary celt concentrations correlate poorly with both colony counts and the cell excretion rate. It is concluded that simple culture of a properly taken urine sample combined with a measurement of the urinary cell excretion rate is adequate for the detection of most urinary infections. In the few instances where these methods do not provide a clear-cut result, colony counting techniques may be of value

The increasing importance currently attached to the diagnosis of urinary infections has led to improvements in the methods available for their detection. In particular, attention has been directed to the enumeration of organisms and of the formed elements present in the urine.

The range of values to be expected from the measurement of bacterial concentration in infected urine has been defined by Kass (1956) and Merritt and Sanford (1958), while more recently Brumfitt, Davies, and Rosser (1961) and Turner (1961) have reported their experience of colony-counting techniques in the investigation of urinary infections.

Renewed interest in the quantitative assessment of the urinary deposit was stimulated by Houghton and Pears (1957) when they described their method for estimating the rate of excretion of white and nonsquamous epithelial cells in the urine. In an investigation of diagnostic procedures in pyelonephritis, Hutt, Chalmers, MacDonald, and de Wardener (1961) concluded that this simple measurement was, by itself, of considerable value.

However, despite the simultaneous development of these two techniques, there appears to have been no direct correlation of results obtained using them. We report here a comparison of the two methods in 51 hospital patients.

\section{MATERIALS AND METHODS}

It has been claimed that pyuria is frequently absent in asymptomatic infections of the urinary tract (Kass, 1956), and in order to test this claim we have selected whenever

Received for publication 30 July 1962. possible patients whose urine showed a growth of organisms on culture, but less than 5 leucocytes per high powero field in the centrifuged deposit. The urine of 28 of the $5 f^{\omega}$ patients fulfilled these criteria, the remaining 23 ranging from the apparently sterile to the grossly infected.

All the patients studied were in general medical of surgical wards of the Royal Infirmary, Sheffield; we ex cluded from the investigation those receiving chemo응 therapy or suffering from neoplastic disease of the urinary tract.

After swabbing the vulva or glans with saline, a mid stream sample of urine was collected for bacterial colony counts, the bladder then being emptied. At an accuratelyp? timed interval of one to two hours afterwards, a second and complete sample was collected for the estimation of the cell excretion rate, again preceded by swabbing of the glans or vulva. Thus the two estimations were performed. on successive samples which were examined independ $\delta$ ently.

We have assumed that the excretion rate of cells andb colony count do not change markedly in successive? samples and have found little diurnal variation in celt excretion rate in five cases although two with significan bacteriuria showed a small and progressive fall in the concentration of organisms throughout the day.

Colony counts were carried out using 10 -fold seria 5 dilutions of urine in normal saline, ranging from 1 in $10 \mathrm{t}$ to 1 in $10^{6}$. One millilitre aliquots from each dilution weres pipetted into sterile petri dishes using a separate sterile pipette for each. Approximately $10 \mathrm{ml}$. of melted, cooled nutrient agar was added to each petri dish and mixed byes rotation. Counts were performed on the plate containing between 30 and 300 colonies, and in our hands the coefficient of variation for the method was $9 \%$. A colony count of 100,000 or more per millilitre of undiluted urine? has been taken to indicate significant bacteriuria. Wळ found this method to be more satisfactory than techniqueso involving the flooding of $0.1 \mathrm{ml}$. quantities on to the 
surface of solid media. The uncentrifuged mid-stream urine was also cultured on blood agar and McConkey agar and the centrifuged deposit examined in the normal way.

The urinary white and non-squamous epithelial cell excretion rate was measured by the technique of Houghton and Pears (1957). In a group of 33 normal patients not included in this series, the mean cell excretion rate was 94,000/hour (range 24,000-237,000/hour). The coefficient of variation for the method, derived from repeated estimations of a single urine sample in normal and infected urines, was $21 \%$. As this magnitude of error might lead to misinterpretation of results close to the upper limit of normal, which we have taken as $200,000 /$ hour (Houghton and Pears, 1957), excretion rates within the range 160 $240,000 /$ hour have always been counted at least twice and the mean value recorded. In seven cases where the cell excretion rate was very high, cells were counted in uncentrifuged urine.

\section{RESULTS}

RELATIONSHIP OF COLONY COUNTS TO CELL CONCENTRATION In Fig. 1 colony counts are compared with the concentration of cells in the timed urine specimen. The criterion of 50 cells $/ \mathrm{c} . \mathrm{mm}$. taken to indicate significant pyuria is that used by Brumfitt et al. (1961). Ten of the 19 samples with high colony counts showed cell concentrations lower than this.

RELATIONSHIP OF CELL CONCENTRATION TO CELL EXCRETION RATE In a large series of patients Little (1962) recently demonstrated the unreliability of employing as an index of pyuria the number of white cells per high-power field in the urine deposit. This widely-used method is likely to be less precise than, but related to, a measured white cell concentration, and in our cases also a comparison of cell excretion rate with cell concentration (Fig. 2) shows that 19 samples with a cell excretion rate of more than $200,000 /$ hour had less than 50 cells/c.mm.

RELATIONSHIP OF CELL EXCRETION RATE TO COLONY COUNT Of the 51 urines examined, 19 had a colony count of $100,000 / \mathrm{ml}$. or more and in all of these the cell excretion rate was greater than 200,000 cells/hour (Fig. 3). However, in 13 cases a high cell excretion rate was associated with a colony count of less than $100,000 / \mathrm{ml}$. Some of these patients had known noninfective renal disease, e.g., chronic glomerulonephritis, and one patient had genito-urinary tuberculosis, but in others the reason for the high cell excretion rate was not apparent.

Four points lie close to the intersection in the lower left quadrant of Fig. 3. Three of these represent samples containing two or more different organisms and the fourth a sample from a patient with acute myeloblastic leukaemia which showed a pure growth

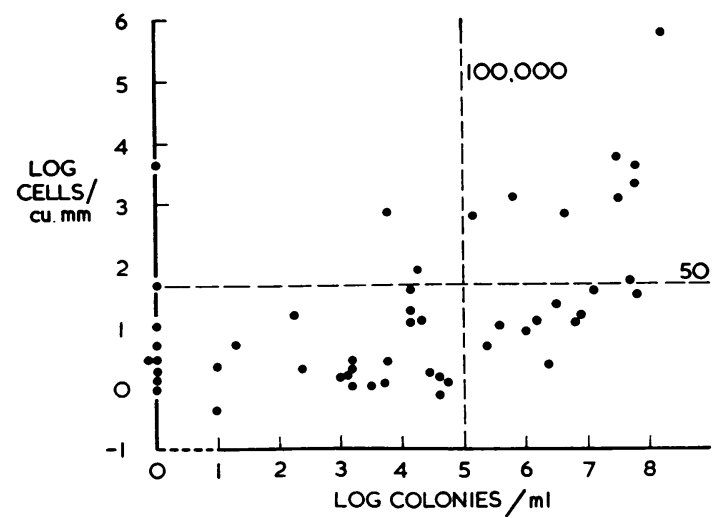

FIG. 1. Comparison of bacterial colony count with urinary cell concentration.

In this and Fig. 3 points plotted at 0 on the abscissa represent samples with less than 10 colonies $/ \mathrm{ml}$. The logarithmic scale starts at 1.

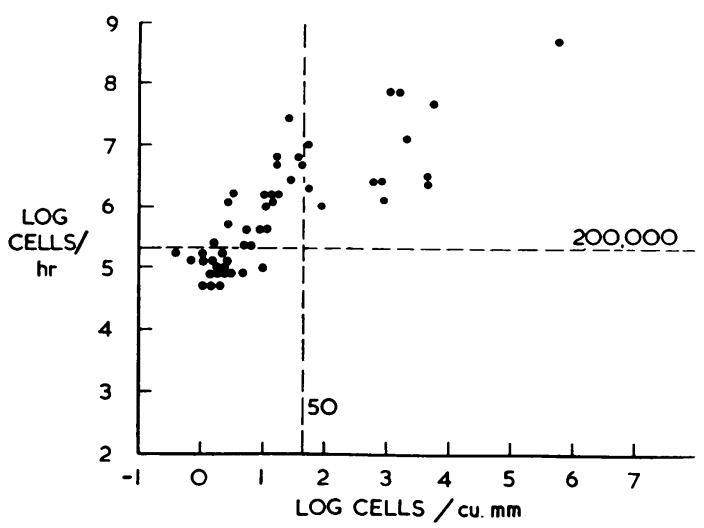

FIG. 2. Comparison of urinary cell concentration with urinary cell excretion rate.

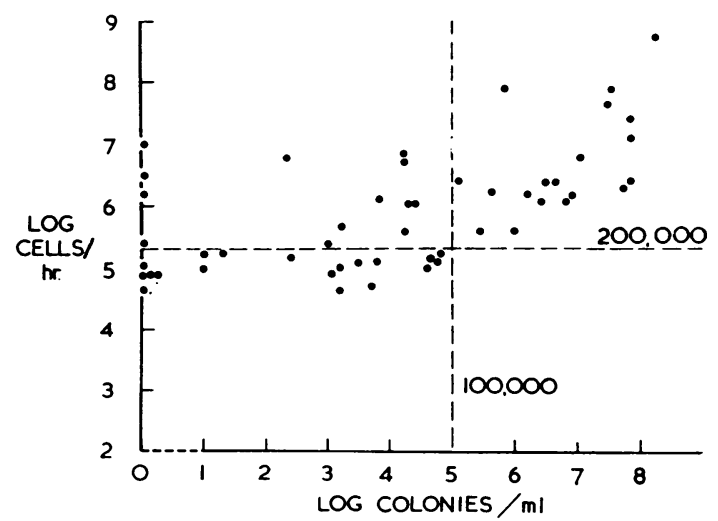

FIG. 3. Comparison of bacterial colony count with urinary cell excretion rate. 
of a $\beta$-haemolytic streptococcus (Lancefield group B).

\section{DISCUSSION}

Although the main object of this investigation has been to compare bacterial colony counts with urinary cell excretion rates, other points have emerged. In the first place, no diagnostic method can be more reliable than the quality of the sample allows. For example, in 46 of our 51 patients culture of a routine urine sample yielded an apparently significant growth of organisms but, when more care was taken in the collection of samples, only 19 of these were found to have more than 100,000 colonies per millilitre. Adequate preparation of the patient is essential if good samples are to be obtained. Secondly, when the two techniques are compared, colony counting has the advantage that the urine samples employed do not require timing and may be kept refrigerated at $4^{\circ} \mathrm{C}$. if immediate examination is not possible, but it requires more time and apparatus and the results are not available for 24 to 48 hours. Measurement of the cell excretion rate, although consuming less time, requires little equipment and gives an immediate result, but has the disadvantages that a timed sample is required which should be examined within two hours.

The number of urine samples involved in this study has been small but the correlation of significant bacteriuria with raised cell excretion rate has been good and no sample with a cell excretion rate of less than $200,000 / \mathrm{hr}$. had a colony count as high as $100,000 / \mathrm{ml}$. This result suggests that a normal cell excretion rate will seldom be associated with signi $\underline{\underline{\underline{\sigma}}}$ ficant bacteriuria. However, the measurement of urinary cell concentrations correlates so poorly withos both colony counts and cell excretion rates thato conclusions drawn from its use will be extremelyo unreliable.

In this series, the presence of a colony count of $100,000 / \mathrm{ml}$. or more was invariably associated witho a moderate to profuse growth of organisms on simple culture of the same specimen. Thus, although colony-counting techniques have been advocated as $\overrightarrow{-}$ screening procedures, we suggest that time ando materials can be saved without loss of diagnostion precision by combining routine culture of properly collected specimens with a measurement of urinary. cell excretion rate.

Despite these procedures, the existence of $a^{\infty}$ urinary infection may still be in doubt, and it is in? these cases that an accurate colony count will be of value.

We wish to thank Professor G. M. Wilson and Dr. J Colquhoun for the use of their laboratories and Professor Wilson and Dr. A. W. D. Leishman for their helpfuf advice and criticisms. Our thanks are also due to the wardw sisters and nurses who helped in the collection of specimens.

\section{REFERENCES}

Brumfitt, W., Davies, B. I., and Rosser, E. ap I. (1961). Lancet, 2, 1059. Hutt, M. S. R., Chalmers, J. A., MacDonald, J. S., and de Wardener, H. E. (1961). Lancet, 1, 351.

Houghton, B. J., and Pears, M. A. (1957). Brit. med. J., 1, 622.

Kass, E. H. (1956). Trans. Ass. Amer. Phycns, 69, 56.

Little, P. J. (1962). Lancet, 1, 1149.

Merritt, A. D., and Sanford, J. P. (1958). J. Lab. clin. Med., 52, 463.

Turner, G. C. (1961). Lancet, 2, 1062. 